\title{
OS RELATOS DE VIAGEM DO SÉCULO XIX COMO FONTES HISTÓRICAS PARA A PRÁTICA DO ENSINO DE HISTÓRIA DA AMÉRICA: ALGUMAS CONSIDERAÇÕES TEÓRICO-METODOLÓGICAS
}

\author{
Carla Viviane Paulino*
}

Resumo: O presente artigo busca discutir os possíveis tratamentos e análises dos relatos de viagens como fonte documental para o professor de História. Para tanto, busca tecer considerações teórico-metodológicas sobre o trabalho com esse tipo de documento e, a fim de elucidar possibilidades de interpretações de seus usos em sala de aula, discute alguns relatos de viagem com o objetivo de demonstrar os possíveis usos e direcionamentos do documento pelo professor.

Palavras-chave: Relatos de viagem. Ensino de História. Representações.

The nineteenth century travel reports as historical sources for the practice of history education in America: some theoretical-methodological considerations

\begin{abstract}
: this article aims to discuss possible treatments and analyzes of travel reports as a documentary source for the history teacher. In order to do so, it seeks to make theoretical and methodological considerations about the work with this type of document and, in order to elucidate possibilities of interpretations of its uses in the classroom, discusses some travel reports with the objective of demonstrating the possible uses and directives of the document by the teacher.
\end{abstract}

Keywords: Travel reports. History teaching. Representations.

Há muito, o trabalho do professor vem exigindo planejamentos de aulas que sejam capazes de promover uma aprendizagem reflexiva, crítica e que posicione o aluno de forma ativa durante o processo de construção do conhecimento. Para tanto, o professor sabe que dele depende a escolha de documentos interessantes e da construção de uma dinâmica de aula criativa e desafiadora. Mais do que um "dador" de aulas, o professor do século XXI que atinge seus objetivos de ensino e aprendizagem é aquele que se compromete com a busca incessante de caminhos para uma aprendizagem crítica e que seja capaz de tornar claro o pressuposto básico do ensino de História - o homem como sujeito histórico.

No que diz respeito ao ensino de História da América do Sul e do Norte, ainda estamos progredindo. Ao tratar do tema, Circe Bittencourt aponta que ainda percor-

\footnotetext{
* Doutora em História Social pela Universidade de São Paulo (USP), especialista nas relações políticas e culturais entre Estados Unidos e América Latina. Atua como professora no Ensino Fundamental, Médio e em cursos de graduação. Concluiu recentemente seu pós-doutoramento em Educação pela UFMT. Email: carlapaulino@hotmail.com
} 
remos o caminho do ensino de nossa história com o objetivo de construirmos as identidades nacionais, mas que embora tenhamos avançado, o estudo da história latinoamericana ainda precisa ser inserido com mais vigor no cotidiano escolar. (Bittencourt,2005).

Neste sentido, o professor deve colocar em debate a ideia de pertencimento. Para tanto, acredito que o caminho do estudo das representações sobre os latinoamericanos em uma perspectiva de história comparada e crítica, que nos permita ver como o "outro" determinou quem seríamos diante do mundo, seja uma alternativa interessante.

Como professora atuante no Ensino fundamental II e Médio, acredito que temos avançado nesse desafio de olharmos de forma dedicada e aprofundada para a história da América Latina, tendo-a como nossa história.

O presente artigo busca apresentar uma fonte documental rica em possibilidades de estudos que demonstram como o "outro" nos representou, quais sejam, os relatos de viagem. Aqui, a partir da análise de alguns excertos de relatos, busco apresentar possibilidades de interpretação desse tipo de fonte, a partir da identificação do lugar de enunciação daqueles que os escreveram e da compreensão da importância, ao se trabalhar esse tipo de documento, de compreendê-los a partir da imbricação entre política e cultura. Com isso, acredito que o professor terá as condições necessárias para escolher textos que representem um determinado tema a ser trabalhado em sala de aula e ser capaz, a partir da prévia fundamentação teórica e metodológica necessária para trabalhar com esse tipo de fonte, de construir sua aula e atingir seus objetivos de ensino e aprendizagem.

Desta forma, proponho discutir os relatos de viagem devido à riqueza que este documento oferece para se trabalhar representações sobre a América do Sul. Para tanto, realizarei uma discussão sobre os relatos de viagem e de alguns aspectos importantes para a compreensão desse tipo de fonte a partir de um eixo teórico específico e após, discutirei dois relatos, ambos escritos por norte-americanos no final da primeira metade do século XIX. Veremos que a compreensão das representações a partir de uma cuidadosa análise do discurso e do contexto em que tais obras foram escritas, nos levam além da possibilidade de percepção sobre a representação de um lugar e nos coloca em um papel muitas vezes desconstrutor desses relatos, fato que pode, ao ser 
trabalhado em sala de aula, levar professor e aluno, juntos, para um caminho rico em contextualizações dos países estudados e abre a possibilidade de ressignificar imagens a partir de um olhar crítico e atento ao conjunto de motivações da escrita.

\section{Os relatos de viagem}

Até o século XIX, os relatos de viagem foram um importante meio de representação do "outro" e de países distantes. Por meio desses interessantes e pitorescos livros, o homem comum podia formar construções imagéticas que muitas vezes (de) formavam homens e países cujo leitor só conheceria através de suas leituras e muitos, através da interpretação de algum homem ou mulher letrado, que lhes contou sobre o que leu.

A denominação "relato de viagem" implica, em geral, em uma narrativa pessoal, que expressa impressões pessoais sobre a experiência da viagem. Todorov observa que, do ponto de vista dos leitores, o autor desse tipo de gênero literário deve narrar "a descoberta dos outros, selvagens de regiões longínquas ou representantes de civilizações não europeias" (Todorov, 2006). Assim, para que o relato de viagem pudesse se enquadrar como tal, este deveria falar sobre civilizações distintas daquela a qual o leitor pertencia. Portanto, era fundamental que a escrita promovesse um "sentimento de alteridade em relação aos seres (e as terras) evocados" (Todorov, 2006a).

Os relatos de viagem sobre o Brasil ganharam força a partir da abertura dos portos brasileiros em 1808. A partir de então, reiniciou a vinda de estrangeiros oriundos das mais diversas regiões do mundo e com os mais diversos interesses no país. Comerciantes, artistas, imigrantes, naturalistas, diplomatas, mercenários, educadores, marinheiros e missionários, muitos tornaram públicas as suas impressões sobre a América do Sul através da publicação de seus diários de viagem.

Durante o século XIX, esses livros se tornaram ainda mais abundantes. Em um livro referência sobre este tema, Miriam M. Leite afirma que sobre o Brasil esse tipo de literatura apareceu em diversas formas: livros compactos ou muito extensos, em forma de romances, para adultos e para crianças e até mesmo sob encomenda do governo brasileiro, com a finalidade de atrair imigrantes europeus. (Leite, 1997). Nas últimas décadas, uma leva de pesquisadores interessados na literatura de viagem, trouxeram 
novas discussões sobre esse tipo de documento. De "fonte fidedigna", o relato de viagem passou a ser visto como fonte privilegiada para análise das imagens e representações no campo da História ${ }^{1}$.

Um outro aspecto a ser observado está relacionado ao tipo de relato produzido. De acordo com Tzvetan Todorov, muitos relatos de viagem foram escritos por representantes do colonialismo, desdobrando-se em três modalidades: militar, comercial e espiritual, ou ainda, tratando-se de "exploradores que se colocavam a serviço de uma ou de outra dessas categorias" (Todorov, 2006c). Aqui, acrescento os representantes das ciências. Os representantes de qualquer um desses segmentos, segundo esse autor, apresentam uma postura comum: um olhar curioso e a segurança de saberse superior em relação à cultura que observava. Para Todorov, esse sentimento de preeminência do europeu em relação às demais culturas permanece até os dias atuais. Atentos as formas de relações de poder indicadas por esse autor que se estabelecem no encontro entre duas culturas, acredito que os viajantes norte-americanos em suas comparações explícitas e implícitas, entre países da América do Sul e os Estados Unidos, buscaram afirmar uma ideia de superioridade do país em que vivia em relação aos países que observaram.

\section{Literatura de viagem e crítica pós-colonial}

Para analisar relatos de viagem, considero relevantes as pesquisas de autores que trabalham dentro do campo conhecido como estudos pós-coloniais, uma vez que estes analisam os discursos produzidos nos relatos de viagem a partir do entendimento do fenômeno do imperialismo, das relações e conflitos entre Norte e Sul e das implicações próprias da globalização. Ademais, muitos dos intelectuais inseridos no campo da crítica pós-colonial buscam pensar as relações desiguais de poder através do prisma da política e da cultura. ${ }^{2}$

Edward Said, considerado um dos fundadores do campo dos estudos póscoloniais, em seu livro Cultura e Imperialismo, afirma que não há como separar a escri-

\footnotetext{
${ }^{1}$ Ver, por exemplo, a importante produção: VV.AA. Revista da USP (Dossiê o Brasil dos Viajantes), São Paulo: n. 30, 1996. Trabalhos mais recentes podem ser vistos em VV.AA. Revista Brasileira de História. (Dossiê Viagens e Viajantes) São Paulo: Anpuh/humanitas, vol.22, n.44, 2002.

2 Para uma introdução do campo da crítica pós-colonial, ver: Chrisman, Laura e Willians, 1994.
} 
ta de um autor da sociedade que o moldou (Said, 1995a). Para Said, as produções literárias não estão desconectadas do contexto cultural, econômico e político em que seus autores estão imersos. Sendo assim, produções como os romances e a literatura de viagens, reproduziram um determinado tipo de discurso que posicionou o homem europeu e também o norte-americano em determinadas situações, bem como o "seu mundo ocidental" e respectivos valores, como superiores em relação ao "resto" do mundo, delimitando assim o espaço doméstico e os outros lugares. Said demonstrou que a cultura não pode ser vista como algo separado da sociedade e da política.

Sobre esse aspecto, como já afirmei em minhas pesquisas sobre o tema, veremos que de fato, em muitos relatos, a experiência dos viajantes descritas em seus relatos serviram mais para reforçar as opiniões que seus autores já tinham sobre os locais visitados e seus habitantes, do que propriamente para construir uma imagem distinta daquela que já carregavam consigo antes de aportarem nesses países. Se houve mudanças na maneira com que refletiram sobre os locais observados, foi no sentido de "comprovarem" o baixo crédito atribuído aos lugares visitados e o lugar de destaque alcançado pelos Estados Unidos (Paulino, 2015).

Por fim, acredito que os relatos de viagem analisados aqui estão inseridos naquilo que Ricardo Salvatore, em seu livro Imágenes de um Império, chamou de máquina representacional. Segundo esse autor, os estudos pós-coloniais permitiram pensar na América do Sul levando em consideração, por exemplo, as ações norte-americanas na região. Assim, Salvatore nos mostra que a região foi alvo do olhar norte-americano desde a primeira metade do século XIX (Salvatore,1998). Para esse autor, os Estados Unidos pretendiam, desde os seus primórdios, o estabelecimento de uma espécie de "império informal" na América do Sul. A estratégia utilizada foi a criação de um conjunto de representações sobre a região, que incluía imagens divulgadas em feiras e exposições universais, notícias e reportagens em jornais e revistas, relatos de viagem, exposições realizadas em importantes museus dos Estados Unidos e trabalhos missionários. As informações coletadas, em muitas situações, eram validadas por universidades e instituições científicas norte-americanas, que assim, contribuiu significativamente nesse processo, endossando e divulgando imagens estereotipadas sobre a América do Sul (Salvatore,1998a).

Portanto, ao se trabalhar com esse tipo de fonte documental, acredito que le- 
var em consideração os aspectos discutidos acima pode direcionar o trabalho do professor para um sentido de reflexões críticas e teoricamente embasadas em estudos recentes e, em minha opinião, extremamente coerentes. Quer-se dizer que, para trabalhar com relatos de viagem como fonte e objeto, seja em uma pesquisa acadêmica, seja como documento primário em sala de aula, o método de análise precisa estar claro. Por outro lado, não pretendo aqui colocar a teoria pós-colonial como única alternativa teórico-metodológica para analisar esse tipo de documento. Mas, sob meu ponto de vista, em minhas pesquisas, cujo, o objeto, foram relatos de viagem escritos por norte-americanos, optei por este caminho devido a fundamental relação entre política e cultura e a ênfase dada ao fato de que esses documentos devem ser tratados como representações que foram construídas a partir de uma perspectiva ocidental e imperialista.

Neste artigo, como já afirmado, pretendo apresentar dois relatos norteamericanos como possibilidade de fontes de análise em sala de aula. Escolho relatos norte-americanos devido ao fato de que esse país, já no século XIX, buscou reproduzir um certo tipo de relação imperialista para com seus irmãos do Sul. Analisar esse tipo de relato em sala de aula, em tempos atuais, onde o modelo norte-americano político e cultural atinge fortemente os países sul-americanos, ajuda o professor a trabalhar em duas frentes, já que contextualizar o relato historicamente e ao mesmo tempo analisar o discurso imperialista ajuda a compreender a atuação política desse país ao mesmo tempo em que desmistifica não apenas imagens estereotipadas sobre o sulamericano, mas também sobre aquele que, via de regra, buscou em seus relatos condenar a América do Sul ao atraso e insignificância, muitas em vezes deliberadamente em prol de seu próprio país.

Por fim, saliento novamente que o lugar de enunciação do escritor seja parte fundamental para se compreender o relato de viagem. A investigação acerca do homem ou mulher que escreveu o relato pode nos dizer muito sobre as representações construídas. Portanto, ao se trabalhar com esse tipo de documentação, há que se somar a compreensão sobre o homem que escreveu e seus interesses com o contexto histórico político e cultural no qual estava inserido. Ignorar um ou outro aspecto empobrece a compreensão do documento. 


\section{Estudando o Brasil Imperial a partir de relatos de viagem}

Como já dito anteriormente, é consenso o fato de que os relatos de viagem não representam fontes fidedignas, mas sim, um documento que sobretudo indica uma determinada representação sobre um tempo e lugar. Dada a riqueza de possibilidades que a análise desse tipo de fonte nos traz, acredito ser um excelente documento para ser trabalhado em sala de aula, levando em consideração os aspectos já mencionados.

Para analisar a construção das representações do homem e da cultura do Brasil oitocentista, apresento aqui, um importante documento elaborado por Thomas Ewbank, objeto de minha dissertação de mestrado. Seu relato de viagem intitulado Life in Brazil or a journal of a visit to the land of the cocoa and the palm (Ewbank, 1856), produziu imagens e representações sobre o Brasil oitocentista que foram veiculadas primeiramente nos Estados Unidos e Inglaterra e depois no Brasil. Ewbank aqui esteve entre fevereiro de 1846 e agosto do mesmo ano. A narrativa, escrita em forma de diário, foi publicada nos Estados Unidos e Inglaterra em 1856. Embora a estada do viajante tenha se restringido ao Rio de Janeiro, as opiniões e julgamentos sobre o que viu não se circunscreveram à capital do país, mas ampliaram-se, devido a forma homogeneizadora de escrita do autor para o Brasil em geral. Para compreender as representações elaboradas por Thomas Ewbank sobre o Brasil e os brasileiros, também foram analisados outros escritos de sua autoria.

Thomas Ewbank nasceu em Durham, Inglaterra, em 1792, mudou-se para os Estados Unidos, em 1819, e abraçou a cultura, a política e o modo de vida norteamericano como poucos. Cientista, inventor e ex-fabricante de canos de cobre e chumbo em Nova York e depois envolvido nos debates científicos que tomaram conta do país, Ewbank, aos 54 anos de idade, visitou à custa própria o Rio de Janeiro, local em que residia seu irmão Joseph Ewbank, casado com uma brasileira. Durante os meses em que esteve no Brasil, o autor quase diariamente saiu em incursões pela cidade a fim de descrevê-la em detalhes.

Em seu relato, podemos encontrar descrições, sempre seguidas de julgamentos do autor, sobre praticamente todos os aspectos do Rio de Janeiro. Nele, observamos que seus julgamentos em geral comparam, direta ou indiretamente, o Brasil com os Estados Unidos. Ao descrever o regime monárquico, o critica ferozmente, menciona o 
republicanismo virtuoso de seu país, os Estados Unidos. Sim, para Ewbank, o fato de ter nascido na Inglaterra sequer é mencionado. Seu país era aquele que havia escolhido e não o de seu nascimento.

Life in Brazil, como indicado, foi publicado somente em 1856, 10 anos após o retorno de Thomas Ewbank aos Estados Unidos. Entretanto, artigos de sua autoria sobre a viagem foram veiculados na Harper's Magazine, importante revista de Nova York. Um primeiro artigo foi veiculado em 1853 e outros dois, em 1855. Nos três, o autor destacou principalmente os temas do catolicismo e da escravidão no Brasil, ainda que, como já mencionamos, ele tenha conhecido apenas o Rio de Janeiro. Mencionar as inserções na Harper's é importante porque seu alcance era amplo, atingindo um grande número de pessoas. ${ }^{3}$ Creio que tais artigos, somados ao livro posteriormente editado, ajudaram a difundir algumas imagens sobre o Brasil nos Estados Unidos que permaneceram, modificadas ou não, até os dias atuais no imaginário norte-americano.

Também foi possível notar a importância do relato de viagem de Ewbank como referência a outros viajantes do mesmo período, que elogiavam seu trabalho tanto por sua capacidade de observação, quanto por sua "coragem" em escrever contundentes críticas dirigidas ao clero, à escravidão, à forma monárquica de governo e à aversão do brasileiro ao trabalho. ${ }^{4}$

A primeira tradução do relato de Ewbank, no Brasil, se deu apenas em 1973, 117 anos após a publicação nos Estados Unidos - pelas editoras Itatiaia/Edusp, seguido de uma segunda edição em $1976 .{ }^{5}$ Todavia, tal fato não impediu que exemplares em inglês circulassem pelo país, pois essa obra, como pode ser observada nos livros de

\footnotetext{
${ }^{3}$ Muitos desses relatos, revistas e jornais podem ser encontrados pela internet, fato que favorece o trabalho do professor. Para maiores informações sobre os artigos citados, consulte: www.harpersmagazine.com e, para acessar exemplares antigos: www.cornelluniversity.org/american studies. Acesso em 10/10/2007.

${ }^{4}$ William Bate fornece alguns dados relevantes sobre a opinião de alguns viajantes norte-americanos sobre Thomas Ewbank. John Codman, por exemplo, escreveu Ten Months in Brazil, em 1867, e elogia Ewbank, considerando-o um "especialista" em arqueologia e mitologia comparada. Considero especialmente interessante a seguinte passagem em que Kidder e Fletcher, dois missionários protestantes e viajantes norte-americanos, citam Ewbank, e recomendam a leitura de seu livro àqueles que desejam saber sobre o lado sombrio do país: "Those who want to know how deep human nature can sink in moral degradation, monarchical imbecility, nopeless superstition, general ignorance, and political demoralisation, read Ewbank's book."

5 A edição brasileira desse relato é: EWBANK, Thomas. A vida no Brasil; ou, diário de uma visita à terra do cacaueiro e das palmeiras. Belo Horizonte: Itatiaia; São Paulo: EDUSP, 1976.
} 
Gilberto Freyre e de Sérgio Buarque de Holanda ${ }^{6}$, vem sendo utilizada como fonte e referência para pesquisa e estudo da História do Brasil oitocentista muito antes de sua edição em português.

Nos Estados Unidos, foi possível encontrar estudos de historiadores e antropólogos, que utilizam os relatos de Ewbank como fonte e, também, algumas Universidades norte-americanas que, na disciplina História do Brasil, utilizam o seu relato de viagem como parte da bibliografia indicada para o curso. ${ }^{7}$

A partir da análise desse livro podemos trabalhar em sala de aula, as imagens e representações do Brasil Imperial. Um tema que pode render análises interessantes é o da escravidão e das concepções sobre as "raças", tendo em vista a quantidade de observações sobre este aspecto no relato. Para tanto, sugiro a contextualização do autor a partir de seu grande envolvimento com a Etnologia norte-americana, que discutia com muito interesse no período em que Ewbank viajou para o Brasil a origem do homem, o clima e a relação deste com a "distribuição das raças no globo" (Banton, 1998). Sobre o clima no Rio de Janeiro e o que este fazia o viajante sentir em sua própria pele, Ewbank escreve:

O calor tão uniforme e a lassidão que o acompanha faz com que as pessoas procurem repouso nas horas da manhã. [...]. Na verdade, os prazeres do verão perpétuo, das flores sempre desabrochando e do clima sempre quente não são tudo aquilo que dizem os poetas, pois se tornam monótonos e deixam de encantar. O corpo definha e a própria mente começa a perder o vigor (Ewbank, 1856a). ${ }^{8}$

O excerto acima, demonstra a crença de que o clima estava associado ao tipo de ser humano que habitava os países ao sul do Equador: preguiçosos e pouco racionais, frutos de um clima que definhava a mente e o corpo, degenerando quem habitava nessas regiões. O viajante vai demostrando, ao longo do relato que o Brasil não era um país com vocação natural para alcançar os estágios mais altos da evolução huma-

\footnotetext{
${ }^{6}$ Autores importantes utilizaram o relato de Thomas Ewbank em livros de sua autoria. Ver: Holanda, 1995, p.151; Freyre, 1954, p.614,712,763; Freyre, 1962, $1^{\circ}$ e $2^{\circ}$ Tomos, p. 35, 37, 527, 539, 696.

${ }^{7}$ Alguns desses casos podem ser econtrados nos seguintes sites: http://dl.lib.Brown.Edu/travelogues/ patrico.html "Thomas Ewbank's depiction of cruelty to brasilian slaves", by Ryan Patrico.; http://retanet.unm.edu/article.pl "Resources for teaching about Americas"; http://dl.lib.brown.edu/ travelogues/lambe.html, "Modeling modern man: american sel-fashioning in nineteenth-century travel literature". Acesso em: 10/11/2007.

${ }^{8}$ Esta e as seguintes são traduções de minha autoria.
} 
na. Suas impressões a este respeito são fortes a ponto de escrever, no prefácio de Life in Brazil, que o atraso de dez anos na publicação de sua narrativa de viagem não implicaria em informações ultrapassadas, pois "como se relacionam a assuntos que são imutáveis, não há nada a lamentar sobre o atraso da publicação" (Ewbank, 1856b). Outro exemplo de tal prognóstico e da relação entre clima e evolução do homem, bem como da superioridade daqueles que habitavam regiões de climas temperados e, portanto, naturalmente superiores pode ser observado abaixo:

\footnotetext{
Deve-se lembrar, todavia, que nenhum povo pode servir de modelo para outro, pois não existem dois povos nas mesmas circunstâncias e condições. A influência do clima, sabemos, é onipotente, e ocupam eles (os brasileiros) uma das maiores e melhores porções das regiões equatoriais. Cabe a eles determinar até que ponto as ciências e as artes dentro dos trópicos podem competir com o progresso feito em zonas temperadas (Ewbank, 1856b).
}

O excerto acima deixa evidente a relação que Ewbank faz entre clima, raça, ciência e progresso. Assim, trabalhar em sala de aula com esses relatos, ao mesmo tempo em que se conhece as teorias raciais do período, é uma forma de proporcionar aos alunos uma compreensão crítica e mais aprofundada sobre o que os discursos e as imagens produzidas nesse relato e lidos por pessoas em várias partes do mundo estavam tentando demonstrar sobre a América do Sul e, em que medida, tais discursos ainda permanecem. Nesse sentido, para professores que desejam trabalhar a questão racial no Brasil, a junção teórica das teorias raciais do século XIX com a análise do relato de Thomas Ewbank podem ajudar a compreender como essas ideias se mesclam aos discursos produzidos na época.

Ao procurar compreender o contexto histórico do período em que Ewbank escreveu, bem como a pesquisa sobre o que esse homem havia realizado naquele período, foi possível conhecer outros textos de sua autoria, os quais indicaram o caminho que fez para chegar a determinada posição sobre alguns temas. Ou seja, para compreender o relato de vigem, foi necessário primeiramente identificar quais ideias ou concepções de mundo estavam presentes no olhar deste viajante sobre o Brasil durante o Segundo Reinado. Portanto, como já dito, cabe ao professor que escolhe trabalhar com determinado relato de viajem fazer uma pesquisa biográfica sobre o viajante, a 
fim de compreender como o seu olhar estava vinculado a sua trajetória de vida e as crenças e interesses políticos e sociais de seu tempo.

Muitos excertos podem ser trabalhados sobre a questão da escravidão no Brasil nesse relato de viagem. Ewbank se comoveu com o estado físico débil dos escravos, que trabalhavam até a morte e sobre os leilões que presenciou: “Assim, vi pela primeira vez em minha vida os ossos e os músculos de um homem, com cada coisa que pertencia a ele, colocados à venda, e seu corpo, sua alma e seu espírito entregues à meIhor oferta" (Ewbank, 1856c).

Ao mesmo tempo em que se comovia com os maus tratos e com a escravidão em si, Ewbank os descreveu como lascivos e de caráter duvidoso. Devido ao interesse do autor sobre a questão racial, muito foi escrito sobre os escravos, embora sobre esse aspecto, nada sobre os Estados Unidos tenha sido dito. Aqui, o autor critica a escravidão no Brasil, mas não comenta o fato de o mesmo regime existir de forma consistente em seu país. Como observo em minha pesquisa, o Estados Unidos, no período em que Ewbank viajou, discutiam de forma intensa a questão e muitos políticos afirmavam que no Brasil, a escravidão e o tratamento despendido aos escravos, era amena, comportamento que deveria ser um exemplo para os Estados Unidos.

Ainda assim, podemos encontrar trechos que de fato correspondem, até onde sabemos, com dados muito próximos da realidade. Utilizar por exemplo, um excerto de Ewbank que descreve de forma dramática um leilão de escravos para discutirmos a forma desumanizada como negros eram tratados no período, pode ser uma boa forma de iniciar um estudo sobre a escravidão no Brasil do século XIX.

Um outro elemento relacionado a escravidão é a associação do trabalho escravo com o impedimento do progresso e da valorização do trabalho:

A tendência inevitável da escravidão por toda parte é tornar o trabaIho desonroso, resultado superlativamente mau, pois inverte a ordem natural e destrói a harmonia da sociedade. A escravidão negra predomina no Brasil, e os brasileiros recuam com algo próximo ao horror dos serviços manuais. No espírito de classes privilegiadas de outras terras, dizem que não nasceram para trabalhar, mas para comandar. Perguntar a um respeitável jovem de uma família em má situação financeira sobre porque não aprende um ofício e ganha sua vida de maneira independente, há dez chances em uma de ele perguntar, tremendo de indignação, se você está querendo insultá-lo! 'Trabalhar! Trabalhar! - gritou um. 'Nós temos os negros para isso'. 
Sim, centenas e centenas de famílias têm um ou dois escravos, vivendo apenas daquilo que os mesmos ganham (Ewbank, 1856d).

Para Ewbank, a escravidão exercia uma enorme influência na forma como os brasileiros enxergavam o trabalho, denegrindo-o. Sua indignação, no entanto, se mostra seletiva e sem grandes críticas. Talvez porque caso decidisse exemplificar, tivesse de mencionar os Estados Unidos que, no período em questão, mantinha escravos não apenas no Sul do país, mas em todo o seu território, como já afirmamos aqui.

Ewbank tratou de muitos temas. O autor escreveu com descaso sobre o catolicismo e suas práticas, salientando o misticismo e a conduta duvidosa dos clérigos:

Eu não tencionava dizer uma única palavra a respeito da moralidade dos padres, mas ouvindo tanto quanto ouço diariamente, é impossível calar. Nem eu nem qualquer outro estrangeiro poderíamos suspeitar que chegasse a tal ponto a corrupção entre o clero, a não ser que tivesse uma situação semelhante à minha, e com os olhos abertos. As palavras de um brasileiro esclarecido aqui citadas, não o são para denunciar indivíduos, e sim o sistema que faz com que eles sejam o que são. "O clero deste país é superlativamente corrupto. É impossível que haja homens piores, ou que se possa imaginar homens piores. Na igreja parecem responsáveis e devotos, porém seus crimes secretos fizeram desta cidade uma Sodoma; há, naturalmente, honrosas exceções, mas estas são muito poucas." Um velho habitante do Rio, que não tem nem motivo nem inclinação para desprestigiar o país e sua moral, acrescentou: "Tudo isso é verdade, e muito mais ainda do que o senhor pode imaginar"[...] Outro, cuja autoridade não seria posta em dúvida se fosse prudente dar-lhe o nome, observa: "Os padres são, sem dúvida, a parte mais licenciosa e dissoluta da comunidade. As exceções são realmente raras. Embora o celibato seja um de seus dogmas, vê-se que quase todos têm família. É um fato evidente, que não admite argumento contrário, que em seus amores eles preferem as mulheres de cor: negras e mulatas" (Ewbank, 1856e).

Importa notar que o viajante condena não o padre, o indivíduo, mas o sistema da Igreja Católica como um todo. Ewbank, ao criticar a conduta do clero brasileiro, buscou o testemunho de brasileiros que também teciam críticas ao catolicismo, como forma de legitimar as afirmações que fez (Paulino, 2015b).

Em contrapartida, o viajante exaltou o protestantismo e seus seguidores. Portanto, Thomas Ewbank opinou, julgou e "condenou" a sociedade que viu no Brasil a partir de concepções e "ideias científicas" que eram discutidas nos Estados Unidos - e 
também na Europa - naquele momento.

Alguns homens da época se consideravam habilitados, a partir de questões postas por algumas "ciências", a identificar determinados patamares de "evolução" nessa ou naquela sociedade. Thomas Ewbank era um deles e assim o fez com o Brasil e, por contraste, com os Estados Unidos (Paulino, 2015c).

Sobre as opiniões que teceu sobre o sistema monárquico e ao trabalho, ficam evidentes a sua própria concepção política e ideológica. Aqui, descobrir qual era a religião do viajante e conhecer os princípios da ética protestante, ajudou a compreender a crítica do autor. Ademais, lembremos que ele era um cientista prático, que, portanto, acreditava na necessidade da prática inventiva do homem para melhorar a sociedade. Assim, para o viajante, a combinação de aversão ao trabalho e escravidão era desastrosa para a sociedade. Obviamente, novamente ele não mencionou a escravidão existente em seu país. Ele prefere focar suas análises comparativas no norte dos Estados Unidos, local do desenvolvimento industrial, mas que não estava livre do trabalho escravo, principalmente nas residências yankees.

Sobre a questão do trabalho e da técnica, convém indicar que o Brasil estava longe de ser considerado um país desinteressado pelo progresso. Assim, uma possibilidade de se trabalhar em sala de aula, seria apresentar a forma como o viajante descreveu o país com relação a esses aspectos e apresentar pesquisas que demonstrem o oposto. ${ }^{9} \mathrm{Sim}$, em muitas situações, os viajantes só enxergavam aquilo que desejavam ver.

Analisando representações sobre a América do Sul a partir de um relatório da U.S. Navy - a Marinha de guerra norte-americana.

Para trabalhar com imagens e representações sobre alguns países da América do Sul, gostaria de discutir aqui sobre o relatório produzido por James Melville Gilliss, capitão da U.S. Navy, astrônomo e comandante de uma expedição astronômica realizada pela Marinha norte-americana ao Chile, durante os anos de 1849 a 1852.

\footnotetext{
${ }^{9}$ Aqui, sugiro a análise do jornal O Auxiliador da Indústria Nacional. Rio de Janeiro: n. 1, nova série, vl. 1, 1846, pp.3-4. Disponível para consulta no Instituto Histórico e Geográfico Brasileiro (IHGB). Esse documento nos mostra o interesse em desenvolver a indústria no país, além de compartilhar notícias de desenvolvimento tecnológico no Brasil e no mundo.
} 
Através desse relatório de viagem, objeto de minha tese de doutoramento, (Paulino, 2015d) podemos identificar, para além das imagens e representações construídas sobre o Panamá, Peru, Chile e Argentina, os interesses científicos, políticos, geopolíticos e comerciais que motivaram a viagem. O relatório da expedição recebeu o título "The U.S. Naval Astronomical Expedition to the Southern Hemisphere during the years 1849-'50-'51-'52'" (Gilliss, 1855).

O relatório foi majoritariamente escrito pelo comandante da expedição, embora tenha a contribuição de especialistas de diversas áreas que analisaram o material recolhido durante a viagem. Gilliss escreveu sobre os países que visitou, quais sejam, Panamá, Peru e Chile e o oficial Archibald MacRae escreveu sobre a Argentina.

Embora a expedição carregasse objetivos variados, a U.S. Navy, enviou Gilliss e sua equipe ao Chile com a missão científica de lá instalar um observatório astronômico, e assim, realizar importantes observações no campo da Astronomia. O objetivo principal da expedição era aprimorar os cálculos da paralaxe solar e estelar, fato que tornaria possível obter as medidas exatas da unidade astronômica (distância da terra ao sol) e assim, obter cálculos precisos das distâncias em terra e em mar. Devido à importância destes cálculos, acredito que este foi o principal elemento motivador para a liberação de fundos para esta expedição pelo governo norte-americano.

A partir dessa viagem, ou motivado por ela, Gilliss cultivou relações com acadêmicos locais e investidores norte-americanos, interessados em expandir seus negócios ao sul do Equador. No que se refere à ciência, uma enorme rede de contatos foi criada a partir dos interesses em torno da expedição astronômica, principalmente entre Estados Unidos, Chile e cientistas da atual Alemanha, indicando assim uma movimentação desses países, paralelo ao esforço inglês, em torno da busca de um lugar de destaque mundial no campo científico.

No intervalo entre as séries de observações, Gilliss viajou pelo Chile, registrando suas impressões sobre o local, a fim de cumprir a agenda de dados que o oficial deveria colher sobre os locais visitados. Em seu percurso de ida, o oficial registrou suas impressões sobre o Panamá e o Peru, além de realizar uma interessante análise sobre os norte-americanos que com ele embarcaram até o Panamá, para depois seguirem à Califórnia, em busca de ouro. O oficial Archibald MacRae, ao fim da expedição, viajou pelo interior da Argentina e produziu um curto, porém interessante relato de sua via- 
gem e nos trouxe novas perspectivas para analisar o relatório oficial da expedição. Ao buscar conhecer os protagonistas da expedição, foi possível descobrir que MacRae rivalizava com Gilliss, desacerto que refletiu no relatório de viagem que escreveu incluído no relatório oficial da expedição. O resultado da expedição foi publicado em 1855 , em quatro alentados volumes.

Ainda que a expedição carregasse primordialmente objetivos científicos, esses não eram os únicos, como já mencionado. A historiadora Mary Anne Junqueira alerta que, entre 1838 e 1901, a U. S. Navy realizou 12 (doze) viagens para a América Latina, as quais carregavam interesses diversos, relacionados entre si no que se refere ao objetivo de compreender de forma mais aprofundada a América do Sul, ainda considerada pouco conhecida, principalmente durante a primeira metade do século XIX (Junqueira, 2007). Justifica-se assim, o particular interesse em descrever os países visitados e relatar o seu potencial para o comércio e a construção de canais marítimos e ferroviários. $^{10}$

Após cerca de três anos no Chile, a expedição retornou aos Estados Unidos e Gilliss deu início à escrita e preparação dos relatórios da viagem. Chama a atenção o número de impressões realizadas para cada relatório: seis mil cópias dos dois primeiros volumes e cinco mil cópias para os demais. Embora não tenha sido possível mapear a distribuição desses relatórios, foi possível descobrir que, por muitos anos, seus registros astronômicos foram úteis para o desenvolvimento da Astronomia.

A partir da análise do relatório da expedição e de toda a tramitação feita pelo governo para que a Marinha obtivesse autorização e subsídio financeiro para realizar a viagem, podemos afirmar que havia a intenção por parte dos Estados Unidos de dominar saberes relacionados à ciência, à cultura, além dos relativos à geopolítica, saberes esses fundamentais para se promover aquilo que os intelectuais do campo da crítica pós-colonial chamam, como já vimos, de "cultura imperial". Em um período em que a Inglaterra se empenhava em demarcar sua atuação na região e se beneficiar das mais variadas formas, tais como influência política, acordos comerciais e construções de vias férreas, os Estados Unidos se movimentaram em direção aos irmãos do Sul, a fim de, minimizar a atuação inglesa e demarcar sua influência na região. Para tanto, era preciso, antes de tudo, conhecê-la. Essa intenção norte-americana tornou-se mais evidente

${ }^{10}$ Sobre tais interesses, foram encontrados dois trabalhos: O'Brien, 2007; e Fifer, 1991. 
na medida em que analisei as detalhadas descrições sobre as regiões visitadas, contemplando fauna, flora, clima, religião, regimes de governo, instituições políticas, sociedades e culturas locais, bem como o potencial para investimento por parte dos Estados Unidos. Assim, a expedição astronômica carregou o objetivo implícito de reunir informações diversificadas sobre a costa oeste da América do Sul. (Paulino, 2015e)

Embora a U.S. Astronomical Expedition tenha sido um importante empreendimento do governo, apresentando como resultado final dados importantes para os interesses científicos e políticos do país, também ofereceu aos leitores uma rica - ainda que duvidosa - descrição dos países sul-americanos já citados. Outro aspecto relevante que ainda não havia sido estudado a partir dessa viagem, diz respeito as tensões existentes entre os interesses científicos nacionais e a necessidade de cooperação transnacional, em especial no campo da Astronomia. Ao levar esse tipo de relato para a sala de aula, os alunos percebem que já na primeira metade do século XIX, o mundo estava em processo de globalização.

Acredito que esse relatório possa ser usado para o estudo de quatro temas: representações e imagens da América do Sul, História da Ciência, Imperialismo norteamericano e História das Relações Internacionais.

Ao visitar os países, Gilliss buscou descrevê-los, tal como Ewbank, como atrasados e governados por políticos corruptos, associados a uma Igreja católica desprovida de seus princípios e valores originais. A descrição da população peruana, especialmente dos indígenas, se repete, tal qual os paradigmas da época:

\begin{abstract}
A população, estimada em 1.500 almas, se parece de acordo com o seu país e as estruturas que habitam. Eles são geralmente pequenos, os índios de cor escura e desleixados no vestir, como o pior de tais nações são normalmente. Pensamentos de limpeza ou modéstia não encontram espaço em suas mentes; eles estão contentes em se agachar sobre os pisos ou areia sob a sombra dos beirados, e balançar em uma rede de grama parece luxo. No entanto, há rostos interessantes e tranquilos entre as mulheres, com seus cabelos longos, escuros soltos, elencados de características submissas. Os descendentes de espanhóis não são numerosos (Gilliss, 1855a).
\end{abstract}

Pequenos, escuros, desleixados, sujos e submissos. Gilliss definiu os indígenas e negros sempre como inferiores em relação aos brancos anglo-saxões. O autor procurou mostrar oportunidades para empreendedores norte-americanos a todo momento, 
demonstrando que os locais não eram capazes de fazer seus países progredirem, devido principalmente a ociosidade que fazia parte de sua compleição. Quando o viajante chegou na Cidade do Panamá, por exemplo, teceu as seguintes considerações:

Eu já disse sobre o número de pessoas que provavelmente habitam dentro ou no entorno da cidade. Quantos destes são permanentemente ocupados em comércios seria difícil de determinar, mas não há dúvida de que o fluxo de americanos aumentou sensivelmente a demanda por produtos nacionais: carpinteiros, alfaiates, sapateiros, chapeleiros, etc., têm para cada pessoa, poucos representantes, que para tanto cobram exatamente cem por cento a mais por seus produtos do que o custo da mesma classe de artigos nos Estados Unidos. A principal causa disso é a indolência absoluta de negros trabalhadores. Estes compõem uma grande parcela da classe trabalhadora, e não estão dispostos a trabalhar um momento depois de terem obtido suficiente para satisfazer os seus apetites durante dois ou três dias. Por conta disso licores intoxicantes são vendidos em cada terceira ou quarta casa e essas lojas recebem mais da metade dos ganhos dos mecânicos. Um pouco de arroz, inhame ou iúcas e frutas nativas, são todos os alimentos de que necessitam. Com a abundância de tais alimentos baratos, uma garrafa de rum ou conhaque do país, um maço de cigarros, eles refestelam sobre o chão ou em redes até que o suprimento de dinheiro se vá, e a fome os obrigue a trabalhar de novo. Antes disso, mesmo que eles possam obter as cargas para transportar sobre os seus ombros, o que normalmente requer curto trabalho e carregamento rápido, bem como grande recompensa, eles não vão para seus ofícios. Aparentemente, as mulheres estão mais inclinadas a trabalhar, mas, sob a influência de um clima enervante, um número muito grande delas aprecia plenamente o "dolce far niente". Com uma túnica de musselina branca ou de um colorido extravagante, tendo amplas franjas plissadas que se estendem do meio do pescoço até os cotovelos e uma saia branca ou de um colorido extravagante semelhante à musselina, embora de diferente material colorido, com grandes babados dos joelhos para baixo e os dedos dos pés presos em chinelos, elas se jogam todos os dias sobre as portas ou varandas em redes ou cadeiras profundas. Como todas as mulheres espanholas, elas arranjam o cabelo com gosto e quando caminham no sol usam chapéus de Guayaquil muito alegremente. Até seis ou sete anos de idade, a natureza fornece todas as roupas de ambos os sexos (Gilliss, 1855b).

O que acabamos de ler acima, infelizmente é uma descrição bastante comum dos negros entre os viajantes europeus e norte-americanos. Gilliss era um homem da ciência e nos Estados Unidos da primeira metade do século XIX, os estudos sobre as raças e os efeitos do clima em diferentes partes do globo vinham sendo amplamente estudados e difundidos, como já analisamos a partir do relato de Thomas Ewbank. 
Utilizar de excertos que retratam os sul-americanos e, em contrapartida, outros textos que desmontam as afirmações e imagens produzidas pelo viajante é sempre um caminho interessante e rico em aprendizagem. Notem que ao se trabalhar com relatos de viagem, estudamos sempre o país relatado em conjunto com o país do viajante.

O interesse norte-americano em avançar no campo da ciência também nos diz muito sobre seu interesse em competir com os europeus. Ademais, o relatório nos mostra uma série de documentos do Congresso que indicam o interesse em se destacar no campo da ciência e, ao mesmo tempo, tornar os mares navegáveis e seguros a partir das observações astronômicas que seriam feitas no Chile. Gilliss usou desse argumento para convencer o congresso da importância de sua expedição:

Estas observações se forem feitas com sucesso na forma proposta, vão apresentar dados unicamente americanos para uma nova e independente determinação do mais importante elemento: que entra em todas as nossas determinações das longitudes, afetando a precisão e segurança de todos esses cálculos e, portanto, da maior utilidade possível não só para o governo, mas para todos os cidadãos empreendedores do nosso país. Neste ponto de vista da expedição recomenda-se um caloroso encorajamento e ajuda eficaz na sua promoção (Gilliss, 1855c).

Assim, podemos perceber que os interesses comerciais caminhavam junto aos demais interesses científicos. Aos estudiosos da História dos Estados Unidos, um relatório oficial pode dizer muito sobre os interesses geopolíticos e comerciais do país.

Sua narrativa sobre o Panamá e os norte-americanos com quem viajou, nos informou muito sobre o tipo de homem que iria construir as representações sobre parte da América do Sul. Elitista, preconceituoso e com os olhos carregados de imagens préconcebidas, Gilliss não tratou de forma desqualificadora apenas os sul-americanos, ele olhou para seus próprios conterrâneos com desprezo e indignação diante do comportamento rústico que apresentavam:

No início, era muito "couleur de rosa." Tanto o navio como os passageiros estavam em roupas de festa, mesmo a natureza, embora um pouco ardente, colocava um sorriso no rosto, e, salvo o calor, a mais linda noite não se poderia desejar. Como o mar estava bastante tranquilo, o mais verde embrião dos caçadores de ouro corajosamente passeava no convés. Grupos de cantores haviam se agrupado em todas as direções, e as glórias do "Sacramento", e "Uncle Ned," com 
uma pauta sobre ocasional "doce lar", ressoou de cada parte. No entanto, "Califórnia", mais do que qualquer outro assunto, provou ser o fardo da canção.

A manhã não trouxe nenhuma mudança de clima, mas as finas vestimentas haviam parcialmente desaparecido, e os homens começaram a aparecer em seu verdadeiro caráter: a maioria dos duzentos e doze sendo aventureiros os quais a porção leste dos Estados Unidos poderia muito bem poupar! É verdade, eram cavalheiros entre eles - isto é, homens cujas consciências controlavam seus atos físicos, mas o número maior ou eram, ou fingiam ser desasseados bem como sem modos. Felizmente, na Era da Califórnia, em viagem, em uma mesa, não era forçado à intimidade com eles (Giliss, 1855d).

Ao destituir de tais homens - que saíam de seus lares em busca de ouro na Califórnia - da "honra" de serem norte-americanos, Gilliss nos informou sobre a visão de parte da elite que não reconhecia as camadas pobres norte-americanas como dignas de carregarem a imagem de seu país para outros lugares do mundo. O papel civilizador baseado no "destino manifesto" não era missão para qualquer um. Até nesse aspecto, a missão só era apropriada para os WASP (White, Anglo-Saxons, Protestants), os quais eram verdadeiramente detentores de tal competência e escolhidos para "iluminar" os irmãos do Sul. Aos demais, deveria restar, como vimos em seu relato, o papel coadjuvante, deslocando os Estados Unidos e alguns da Europa como os protagonistas. Não há dúvidas de que os Estados Unidos queriam firmar-se na América Central e do Sul. Portanto, a imagem deles não poderia ser manchada pelos norte-americanos pobres que passavam por essas regiões, de acordo com a mentalidade de Gilliss. (Paulino, 2015f).

Ademais, saliento que nem sempre os relatórios publicados revelam todas as informações que foram repassadas ao governo. Sua ida e volta pelo Panamá denotaram o interesse dos Estados Unidos pela região que já mantinha investidores concentrados na construção de estradas de ferro para facilitar o acesso dos norte-americanos para a Califórnia. Além disso, o tratado firmado entre a Grã Colômbia e os Estados Unidos já indicavam a intenção norte-americana sobre a região. Mas isso, obviamente, não foi tratado pelo oficial em seu relatório. (Paulino, 2015g). No entanto, pode ser tratado pelos historiadores do tempo presente a partir de documentos que indiquem essas afirmações, proporcionando um instigante trabalho investigativo em sala de aula, especialmente no ensino superior em História ou em Relações Internacionais. 
Finalizo aqui, sugerindo que o caminho inverso também é muitíssimo interessante. Os relatos de viajantes sul-americanos sobre os Estados Unidos, especialmente os da segunda metade do século XIX, oferecem inúmeras formas de representação daquele país. Se, por exemplo, ao ler Viajes, de Domingo Faustino Sarmiento, (Sarmiento, 1993) notamos um relato repleto de elogios aos norte-americanos, o mesmo não acontece ao lermos o argentino Vicente Gregório Quesada, ou boliviano Alberto Gutiérrez, ambos diplomatas e intelectuais de prestígio em seus países. Em seus relatos sobre os Estados Unidos, podemos trabalhar o olhar crítico e resistente para com as políticas imperiais propostas pelo governo norte-americano no final do século XIX, somadas a uma tentativa de, tal como vimos nos relatos produzidos pelos norteamericanos, manchar a imagem do governo, da população e das leis estadunidenses. Eis aqui uma fonte que proporciona ao professor analisar a questão das identidades propostas pelos dois pensadores em contraposição às imagens e representações construídas por eles sobre os Estados Unidos. ${ }^{11}$

\section{Referências bibliográficas}

BITTENCOURT, Circe M. F. Ensino de história da América: reflexões sobre problemas de identidades. Revista Eletronica da ANPLHAC, n. 4, 2005.

BANTON, M. Racial Theories. Cambridge: Cambridge University Press: 1998.

BORM, Jam. Defining travel: on travel book, travel writing, and terminology. In HOOPER, GLENN; YOUNGS, Tim(ed). Perspectives on travel writing. Hants/Vermont: Ashgate, 2004.

CHRISMAN, Laura; and Willians (org.). Colonial discourse and post-colonial theory. A introduction. In: Colonial discourse and post-colonial theory. A reader. New York: Colúmbia University Press, 1994.

EWBANK, Thomas. Life in Brazil our journal of a visit to the land of the cocoa and the palm. New York: Harper \& Brother, 1856.

CHARTIER, Roger. A história Cultural: entre práticas e representações. Lisboa: Difel; Rio de Janeiro: Bertland Brasil, 1990.

FREYRE, Gilberto. Casa-Grande \& Senzala. Rio de Janeiro: José Olympio, 8 a edição, 1954.

\footnotetext{
${ }^{11}$ Esses e muitos outros relatos estão disponíveis na internet, facilitando o trabalho do professor.
} 
FREYRE, Gilberto. Ordem e Progresso. Rio de Janeiro: José Olympio, $2^{\text {a }}$ edição, 1962.

FIFER, Valerie J. United States perceptions of Latin America, 1850-1930: a "New West" south of Capricorn? Manchester: Manchester University Press, 1991.

GILLISS, James Melville. The U.S. Naval Astronomical Expedition to the Southern Hemisphere during the years 1849-'50-'51-'52. Washington: A.O.P. Nicholson Printer, 1855. VIs.I, II, III, VI.

HOLANDA, Sérgio Buarque. Raízes do Brasil. São Paulo: Cia das Letras, 26a edição, 1995.

JUNQUEIRA, Mary A. Ciência, técnica e as expedições da marinha de guerra norteamericana, U.S. Navy, em direção à América Latina (1838-1901). Varia história. [online]. 2007, vol.23, n.38, pp. 334-349.

GUTIÉRREZ, Alberto. Notas e impresiones de los Estados Unidos. Santiago de Chile: Imprenta Cervantes, 1904.

LEITE, Miriam Moreira. Livros de Viagem (1803-1900). Rio de Janeiro: Editora UFRJ, 1997.

PAULINO, Carla Viviane. O império do atraso: Etnologia, Política e religião nas impressões sobre o Brasil de um inglês radicado nos Estados Unidos (1846-1856). São Paulo: Alameda, 2015.

PAULINO, Carla Viviane. A viagem da U. S. Astronomical Expedition (1849-1852): observar estrelas e relatar a América do Sul. São Paulo: FFLCH-USP, Departamento de História, 2015.

O'BRIEN, Thomas. Making the Americas: The United States and Latin America from the age of revolutions to the era of globalization. Albuquerque: University of New Mexico Press, 2007.

QUESADA, Vicente G. Recuerdos de mi vida diplomática: misión en Estados Unidos (1885-1892). Buenos Aires: J. Menéndez, 1904.

SAID, Edward W. Cultura e Imperialismo. São Paulo: Companhia das Letras, 1995.

SALVATORE, Ricardo D. The Enterprise of Knowledge: Representational Machines of Informal Empire. In: LEGRAND, Catharine C.; SALVATORE, Ricardo D. (orgs.). Close Encounters of Empire: Writing the Cultural History of. U.S. - Latin American Relations. Durham: Duke University Press, 1998.

SARMIENTO, Domingo F. Viajes por Europa, África y América 1845-1847 y Diario de 
Gastos. Fondo de Cultura Económica. Bs.As., 1993.

TODOROV, Tzvetan. "A viagem e seu relato". In Revista de letras da UNESP. São Paulo: vol. 46, n.1, 2006.

Artigo recebido em 08 de novembro de 2016 e aprovado em 02 de julho de 2017. 